\title{
The Validity Study on Students Online English Autonomous Learning System
}

\author{
TAN Jie ${ }^{1, a}$ \\ ${ }^{1}$ School of Foreign Languages and Cultures of Panzhihua University, Panzhihua 617000, China \\ atanjie1209@126.com
}

Keywords: Validity Study; Constructivism Learning Theory; Autonomous Learning System; English learning

\begin{abstract}
Guided by the constructivism learning theory, this study based on the teaching practice of English autonomous learning system online, by investigating students' English autonomous learning ability of English online self-assessment and the attitude to autonomous learning, and the main factors influencing the heard that autonomous learning effectiveness, and the effectiveness of online English autonomous learning system for empirical research. Survey, online English autonomous learning system can reduce students' anxiety, arouse their interest in learning English, effectively improve the autonomous learning ability, promote the improvement of college English teaching quality in an all-round way. At the same time, the study also confirmed that the teacher's supervision and the cultivation of students' learning strategy is an important factor influence on the effectiveness of heard of autonomous learning.
\end{abstract}

\section{Introduction}

Network information technology in English teaching will become an unstoppable trend. Information resource that is learning material is always open and constantly updated, the choice of learning content is autonomous and individualized, and learning is no limit of time and space. However, this is loose, uncertainty, difficult to control completely let students online autonomous learning results often leads to its aimlessly roaming in the net sea, sometimes encounter some bad site, its content is also a negative effect on the students [1]. Therefore, in order to will be dispersed, disorderly resources together and make learners, efficient and convenient to use it in their own learning, and on a larger scale to achieve the sharing, so as to realize the application of the Internet under the network interconnection, implement effective learning resources sharing. Through the establishment of online English autonomous learning system, filtered to English teaching resources on the Internet, will be the best English teaching resources integration, and at different levels for English learners, design, edit, different content, anyone who wants to learn English, or want to improve my English, open the web page can be convenient to find you need of learning content [2].

At the same time, online English autonomous learning system validity study is very necessary. Guided by the constructivism learning theory, this study based on the teaching practice of English autonomous learning system online, by investigating students' English autonomous learning ability of English online self-assessment and the attitude to autonomous learning, and the main factors influencing the heard that autonomous learning effectiveness, and the effectiveness of online English autonomous learning system for empirical research. Through the empirical study confirmed that the system is popular with students, to a certain extent, improve the students' English level, can maximum limit promote students' English autonomous learning, after the perfect can be promoted.

\section{The overall function for online English learning system}

Depending on the target system can be divided into three functional modules, an administrator module, a module is a teacher, and the last one is the student module. After the administrator login is successful, the management of personal information, users and their class teachers; teachers after successful login personal information, student information, student learning, student test conditions 
and student management, student according to their classes, you can register after a successful login, students can manage personal information, you can complete the learning task, checking the learning process, using a dictionary tool, participate in a variety of test and query results, you can post and reply to operate [3-4]. The overall function modules college English online learning system design shown in Figure 2.

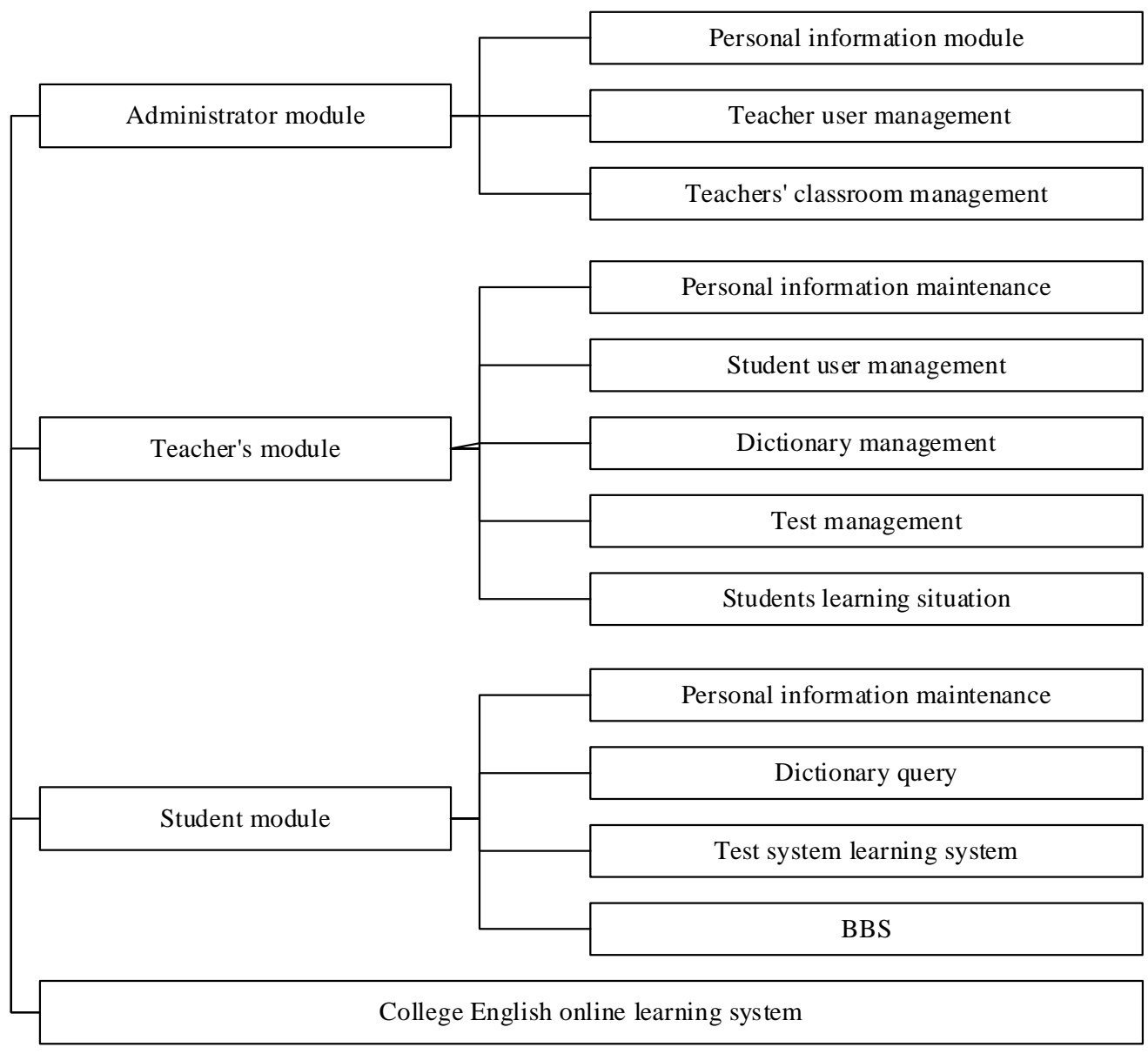

Figure 2. College English online learning system's overall function module

Administrator module includes personal information maintenance module, user management module and teacher classroom management module. Administrator module is used to check or modify personal information, personal information manager module. Administrator user management module interface to the teacher, the teacher can be a user query, add, delete or modify the operating system will meet the requirements listed in the user information table according to the query entered, and then the teacher administrators can add user information, delete, or modify operation, if you do not have a successful operation, the result is a list of the teachers' information. After the success of the operation will exit the screen. Management class as well. Teacher module includes personal information maintenance module, the student user information module, dictionary management module, test module, student learning modules and forum management module. Personal Information Student module for students to manage their own maintenance, dictionary lookup, student module testing, student learning and forums.

\section{Architecture of college online English learning system}

Let the user to complete their task, functional requirements define the developer must achieve the function of software. In view of the existing traditional remote diagnosis and feedback of teaching educational development and design problems, learning English online based on ASP system. Network technology, has a broad space for development. The design is suitable for Internet release, the development includes the development of front-end applications, the establishment of 
background database. Integral structure using B / S structure, using ASP [5]. Net dynamic web technology, by using the SQL Server 2005 database development. It completely break the existing school education system, the limitation of time and space, break the teacher as the main approach to education, expand the scope of the object of education, effective use of various channels to provide educational resources advantage. This is not only in line with the actual situation of our hospital, also conforms to the developing trend of world education. English online learning system architecture as shown in figure 3.

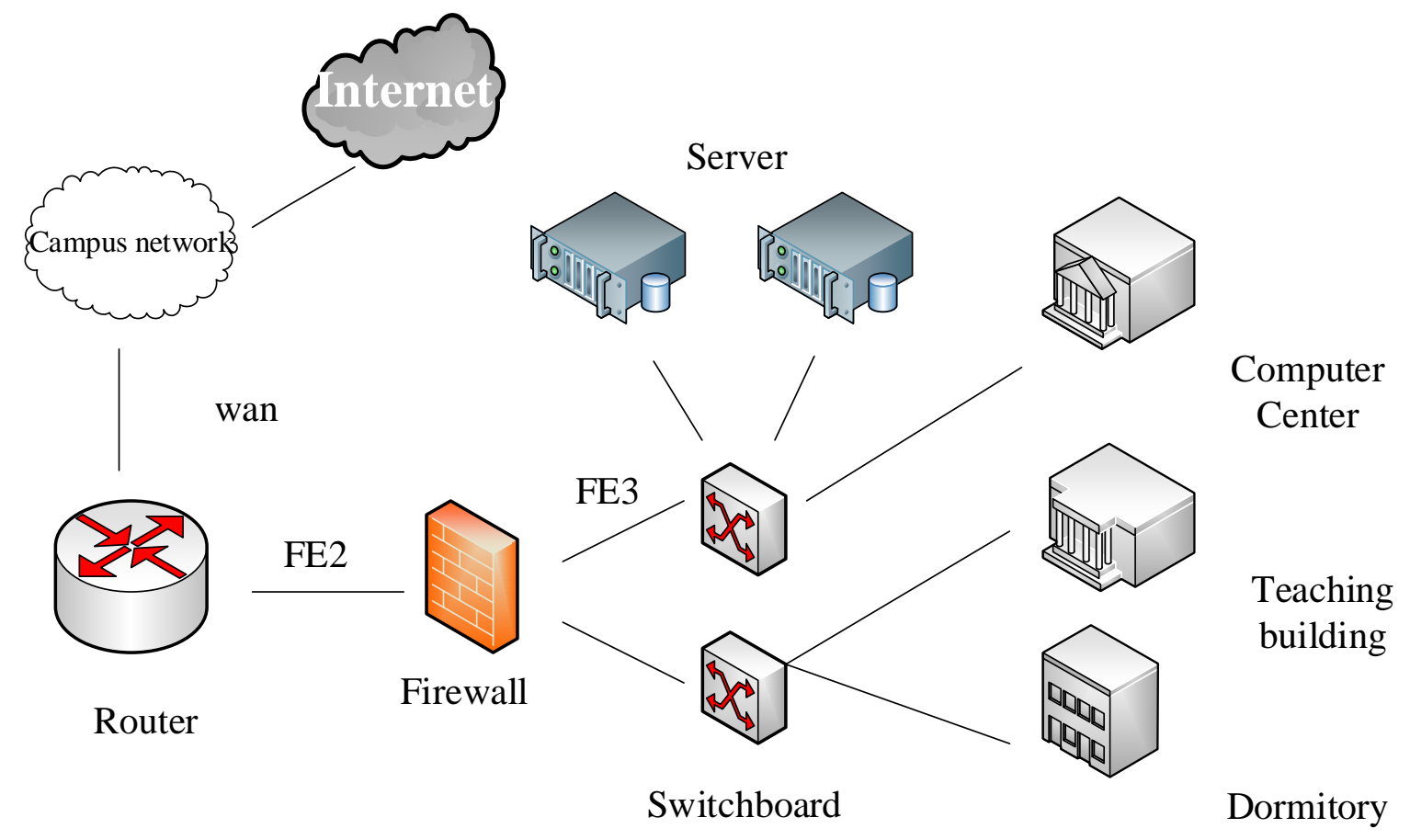

Figure 3. Architecture of college online English learning system

The server is connected to the switch, connected to the campus network by hardware firewall and router; on the other hand, a switch and a room, building a computer connected to the computer and the student dormitory. This forms the basic structure of the network system. The system is mainly to the internal network using a small scale, such a system load of small, high safety, and a security system of execution speed and efficiency.

\section{The Online English learning system validity analysis}

This paper selected the two levels of class as effectiveness experiment analysis object, a total of 50 people, the duration of three months. In order to evaluate objectively the progress of their English, and improve the credibility of the experiment, first of all, based on the level of English of two classes before the test, test results show that the two classes of English level, can be used to compare research. In the experimental classes in English autonomous learning system after three months, with the selected test paper to test after two classes. By comparing the class A and class B English grades and test scores before and after experimental classes, can know whether the system to promote the improvement of the experimental class students English level, and English learning system in students' autonomous learning plays an important and effective role. Finally, using SPSS statistical analysis software after the exam results are paired sample test, it is clear whether experimental classes can be drawn from English progress.

In addition to use objective means, test and questionnaire, teachers' observation of the students in the experimental process is also very important. In students' autonomous learning in the process of using the learning system should always ensure that the teacher is present, solve the student to utilize the system encountered difficulties, maintain the order of students' learning, what is more important for students to autonomous learning circumstance timely observation, record, the 
effective use of the system at the same time, necessary auxiliary role in the analysis of experimental results.

In the paired samples test table, can find the class have significantly difference, a system in the use of English learning English test scores before and after the progress. Results showed that most of the students like English, to improve my English level, in addition to assignments, rarely on English autonomous learning, one of the reasons is not to find the right, the system resources; Part of autonomous learning of students, complain about problems difficult to find the answer. English autonomous learning system for students autonomous learning, providing a large number of learning resources, students can have a problem through the communication between teachers and students module, ask the teacher or other students, is bound to play an effective auxiliary in students' English autonomous learning. At the same time, most of the students prefer learning English through English autonomous learning system; For the system itself, like the course students more center module and video module; Most of the students think that the system to its effective auxiliary role in the English autonomous learning, can improve the English level; Questionnaire also shows that although students like autonomous learning system, but is not to say that no longer need to teachers, students instead puts forward more requirements on the teacher's role.

\section{Conclusion}

Generally speaking, the online English learning system is popular with students, to a certain extent, improve the level of English for most of the students, to promote students' English autonomous learning maximum results. However, it must be admitted that a lot of deficiencies. Online English learning system in some aspects of the imperfect had a certain influence on the result of the experiment, especially the deficiency of students' autonomous learning strategy and make the system failed to give full play to the effect, on the other hand, teachers on the role of failed to appropriate changes also affect the students learning through the system. Therefore, in order to make the system achieve the best application effect, it is necessary to cultivate students' autonomous strategy, guide on the changing role of teachers, the online English learning system to continuously improve. The author will continue to study, will eventually mature system applied to the floor, and to the outside.

\section{Acknowledgements}

The project "The research on the development and comprehensive utilization of English curriculum resources" of the 12th five-year plan of the China Education Society, the subproject " The research on the development and comprehensive utilization of College English curriculum resources " (item number 01060129 - DX23) .

\section{References}

[1] Benson, Phillip. Teaching and researching: Autonomy in language learning. Routledge, 2013.

[2] Sanprasert, Navaporn. "The application of a course management system to enhance autonomy in learning English as a foreign language." System 38.1 (2010): 109-123.

[3] Zorko, Vida. "Factors affecting the way students collaborate in a wiki for English language learning." Australasian Journal of Educational Technology 25.5 (2009): 645-665.

[4] Wang, Minjuan, et al. "The impact of mobile learning on students' learning behaviours and performance: Report from a large blended classroom." British Journal of Educational Technology 40.4 (2009): 673-695.

[5] Drexler, Wendy. "The networked student model for construction of personal learning environments: Balancing teacher control and student autonomy."Australasian Journal of Educational Technology 26.3 (2010): 369-385. 